\title{
Canvas Acadêmico: uma plataforma para estruturação de ideias de projetos em ambiente universitário
}

\author{
Marisângela Pacheco Brittes ${ }^{1}$, Guilherme da Cunha Guimarães', Victor Carli \\ ${ }^{1}$ COENS - Coordenação de Engenharia de Software - Universidade Tecnológica \\ Federal Paraná (UTFPR) \\ Estrada para Boa Esperança, S/n - Zona Rural, Dois Vizinhos - Paraná - Brasil \\ CEP 85660-000 \\ mbrittes@utfpr.edu.br,g-guimaraes@live.com,victorcarlibr@gmail.com
}

\begin{abstract}
Resumo. Este trabalho apresenta o Canvas Acadêmico, uma plataforma de software que visa apoiar alunos e professores na estruturação de seus trabalhos acadêmicos de forma visual, interativa e simplificada. Com esta plataforma espera-se que a construção de projetos e trabalhos acadêmicos seja facilitada, motivando o desenvolvimento científico e tecnológico por parte de alunos e professores, tornando também familiar aos mesmos, estruturas já utilizadas para modelagem de negócios e empreendedorismo, fomentando a aproximação desses ambientes distintos.
\end{abstract}

\section{Cenário de uso}

A proposta desse projeto surgiu a partir do trabalho Business Model Canvas ou Canvas do Modelo de Negócios, proposto por Ostelwalder em sua tese de doutorado (Ostelwalder, 2004). Sua proposta inicial era desenvolver uma ontologia para apoiar a modelagem de negócios com foco em inovação, a partir das mudanças promovidas pela tecnologia em todos os segmentos de mercado.

O sucesso deste modelo foi imediato, com a publicação de um livro com o mesmo nome, Business Model Canvas (Osterwalder, 2010) e várias empresas adotando esse modelo como ferramenta para apoiar a construção de novos produtos, serviços e empreendimentos. Logo surgiram variações do modelo, como Business Model You (Clark, 2013), voltado a modelagem de serviços e qualificações próprias do indivíduo, assim como Value Proposition Model (Osterwalder, 2014), para modelar somente a proposta de valor dos negócios das empresas. Outro modelo Canvas proposto recentemente foi um Canvas do Modelo de Projetos (Junior, 2013), criado para estruturar os principais componentes de um projeto em sua fase inicial, antes do projeto efetivamente começar.

O conteúdo criado a partir destes modelos trouxe interessantes contribuições, pois conseguem agregar conceitos importantes de estratégia e inovação em um modelo simples e visual, chamado de Canvas do Modelo de Negócios. Trata-se de uma ferramenta para descrever como uma organização cria, entrega e captura valor ou, em outras palavras, descrever o seu modelo de negócios.

O Canvas de Modelo de Negócios é composto de nove blocos cuidadosamente selecionados e organizados, que descrevem as áreas-chave para se planejar ou reestruturar um negócio, conforme apresentados na figura 1 a seguir: 
V Congresso Brasileiro de Informática na Educação (CBIE 2016)

Anais dos Workshops do V Congresso Brasileiro de Informática na Educação (CBIE 2016)

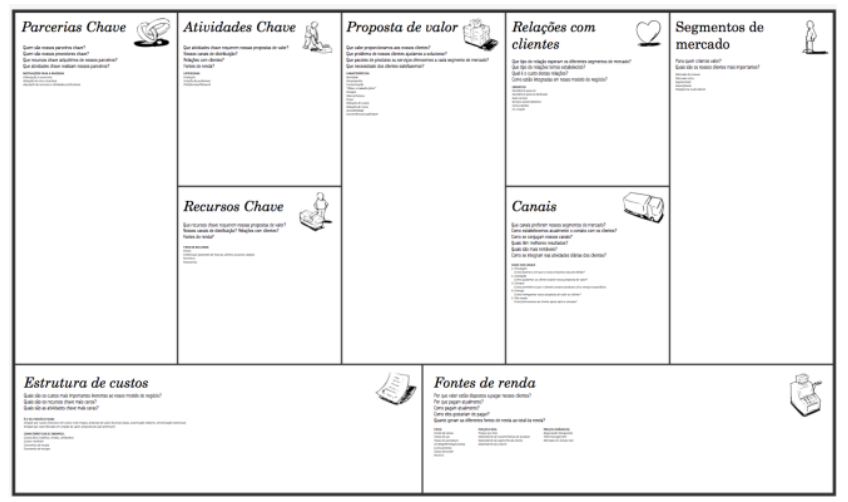

Figura 1: Business Model Canvas proposto por Ostewalder.

No Brasil uma iniciativa semelhante foi proposta por Finocchio para a área de gerenciamento de projetos, denominada Project Model Canvas ou Canvas para Modelo de Projetos (Junior, 2013), para estruturação dos projetos em sua fase inicial visando minimizar a burocracia clássica inerente a essa área, conforme observado na figura 2:

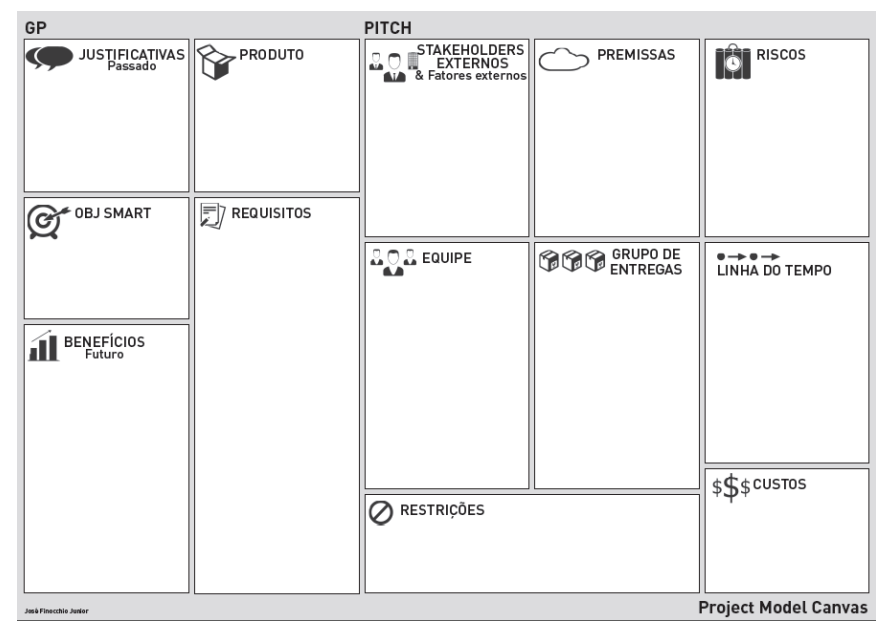

Figura 2: Project Model Canvas proposto por Finocchio.

Assim como na área empresarial, existe a necessidade de se estruturar ideias referentes a projetos e trabalhos acadêmicos de modo simplificado e visual, para que a partir de sua definição inicial possam ser corretamente escritos conforme modelos e normas propostos (ABNT e normas próprias da universidade).

O Canvas Acadêmico apresenta uma proposta para utilizar a estrutura em blocos do Canvas do Modelo de Negócios como base para a criação de um Canvas composto por componentes do mundo acadêmico, utilizadas para escrever um trabalho ou projeto de pesquisa, como mostrado na figura 3: 
V Congresso Brasileiro de Informática na Educação (CBIE 2016)

Anais dos Workshops do V Congresso Brasileiro de Informática na Educação (CBIE 2016)

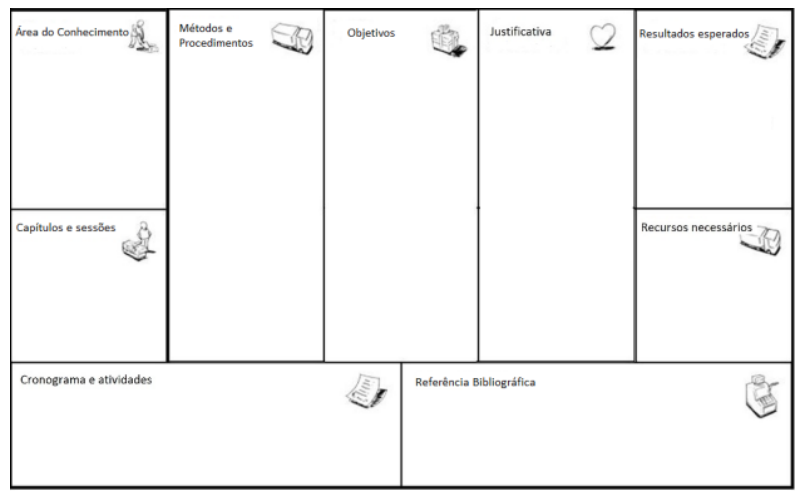

Figura 3: Canvas Acadêmico proposto.

Durante as disciplinas de metodologia de pesquisa cientifica dos mais variados cursos nas universidades, os alunos apresentam certa dificuldade em assimilar e relacionar os itens necessários para desenvolver um trabalho acadêmico, seja artigo, projeto de pesquisa ou trabalho de conclusão de curso.

Essa dificuldade em organizar o pensamento, atrasa e desmotiva os mesmos, fazendo com que sintam como se esse tipo de trabalho fosse "pesaroso", quando poderia ser "prazeroso".

As aulas totalmente teóricas e expositivas não conseguem contemplar todas as necessidades dos alunos, os quais necessitam de apoio visual e dinâmico para que possam melhor desenvolver seu raciocínio para a estruturação de seus trabalhos

Espera-se que com esta proposta, por apresentar a possibilidade de modelar seu trabalho acadêmico de forma visual, interativa e compartilhada, os alunos se motivem, melhorem a qualidade de seus trabalhos e aumentem a produção científica de qualidade em todas as universidades que quiserem adotar esse modelo, que poderá ser utilizado por qualquer curso em todas as áreas do conhecimento.

Também facilita a discussão de ideias para o trabalho com os orientadores ao compartilhar o projeto através do software, dispondo de elementos visuais de fácil acesso para assim efetuar mudanças ou incrementos nos itens do trabalho de forma simples e colaborativa.

\section{Desenvolvimento}

Para o desenvolvimento adequado do Canvas Acadêmico, foram estudados os públicos alvo através de pesquisas, analises e entrevistas com alunos e professores universitários na própria UTFPR (Universidade Tecnológica Federal do Paraná) e de outras Universidades. Este projeto contou com o apoio da UTFPR através do Programa de Bolsas para o Desenvolvimento de Recursos Educacionais Abertos (PIBEA) e do Programa de Bolsas de Fomento às Ações de Graduação da UTFPR.

Após o desenho inicial dos quadros que compõe o Modelo Canvas Acadêmico, foi criado um grupo, a partir da identificação de alunos interessados em desenvolver trabalhos acadêmicos, os quais, não possuíam conhecimento prévio em metodologia da 
pesquisa. Foram distribuídos Canvas Acadêmicos impressos para que os mesmos preenchessem com suas ideias usando post-its, anotando os pontos principais de suas ideias de projetos nos respectivos quadros.

Os alunos participantes desse grupo conseguiram estruturar suas ideias iniciais a partir do Modelo Canvas Acadêmico, o qual foi criado para ser usado de forma intuitiva, sem que houvesse a necessidade de muitas explicações sobre seu conteúdo e composição.

Através dessas validações entendeu-se que o modelo proposto estava maduro para ser adaptado para formato de software, com todas as facilidades que os meios eletrônicos proporcionam para otimização do trabalho.

Visando atender as necessidades desses públicos, o Canvas Acadêmico foi desenvolvido com acesso em 3 plataformas: (i) website, onde os usuários podem efetuar Login e ter acesso aos recursos online, além da documentação, arquivos para impressão, vídeos e conteúdo explicativo; (ii) Plataforma iOS com recursos off-line e de sincronização online; (iii) Plataforma Android com recursos off-line e de sincronização online.

A versão online pode ser acessada no endereço www.canvasacademico.com, as versões iOS e Android estão sendo homologadas em suas lojas para serem disponibilizadas em breve para o público.

Para o desenvolvimento das aplicações foi utilizada a linguagem JavaScript e o banco de dados PostgreSQL, no modelo Cloud Computing tendo Digital Ocean como hosting. Todo o produto tecnológico desta versão do Canvas Acadêmico está disponível para acesso e consulta no endereço acima, sob licença GNU 3.0.

\section{Apresentação do Software}

O Canvas Acadêmico pode ser acessado pelo endereço www.canvasacademico.com e em breve pelas plataformas iOS e Android, a partir de suas respectivas lojas. Vídeos explicativos sobre a plataforma podem ser encontrados no Canal Youtube denominado Canvas Acadêmico.

O acesso a plataforma web se dá por meio de um cadastro com informações breves sobre o usuário, login e senha. Após o primeiro acesso, pode se conectar automaticamente à plataforma, conforme ilustrado na figura 4 a seguir: 
V Congresso Brasileiro de Informática na Educação (CBIE 2016)

Anais dos Workshops do V Congresso Brasileiro de Informática na Educação (CBIE 2016)

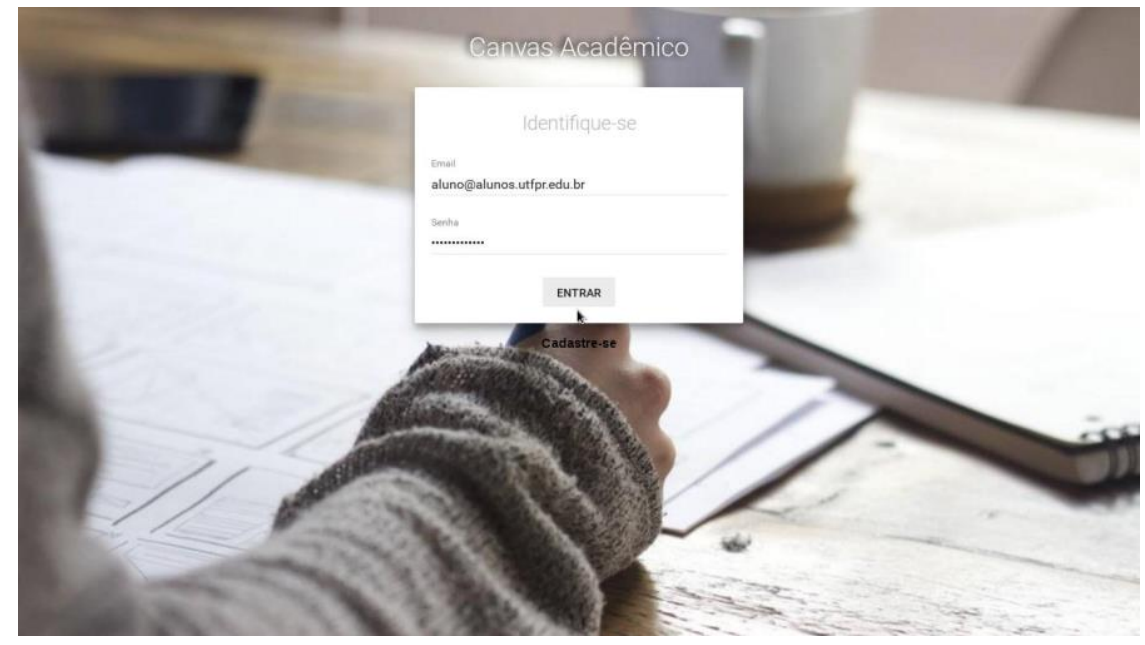

Figura 4: Tela de acesso ao Canvas Acadêmico.

Após efetuar login, o usuário poderá criar novos projetos ou editar projetos existentes, a partir da sua área de projetos, assim como compartilhar projetos com outros alunos e professores para que possam colaborar na composição de ideias, conforme a figura 5:

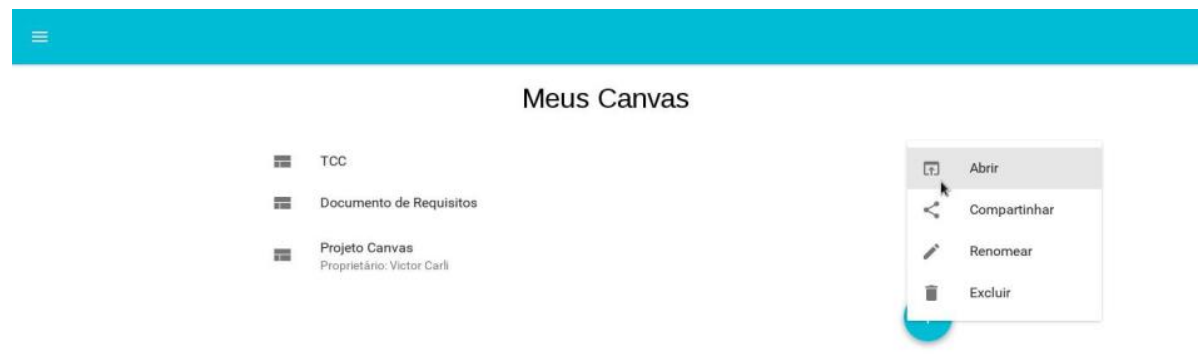

Figura 5: Área de projetos Canvas com funcionalidades

A partir da seleção do projeto, será exibido o Canvas Acadêmico abrangendo todos os campos, onde o usuário poderá começar a inserir post-its virtuais com as ideias referentes a cada área do projeto, conforme a figura 6 a seguir: 
V Congresso Brasileiro de Informática na Educação (CBIE 2016)

Anais dos Workshops do V Congresso Brasileiro de Informática na Educação (CBIE 2016)

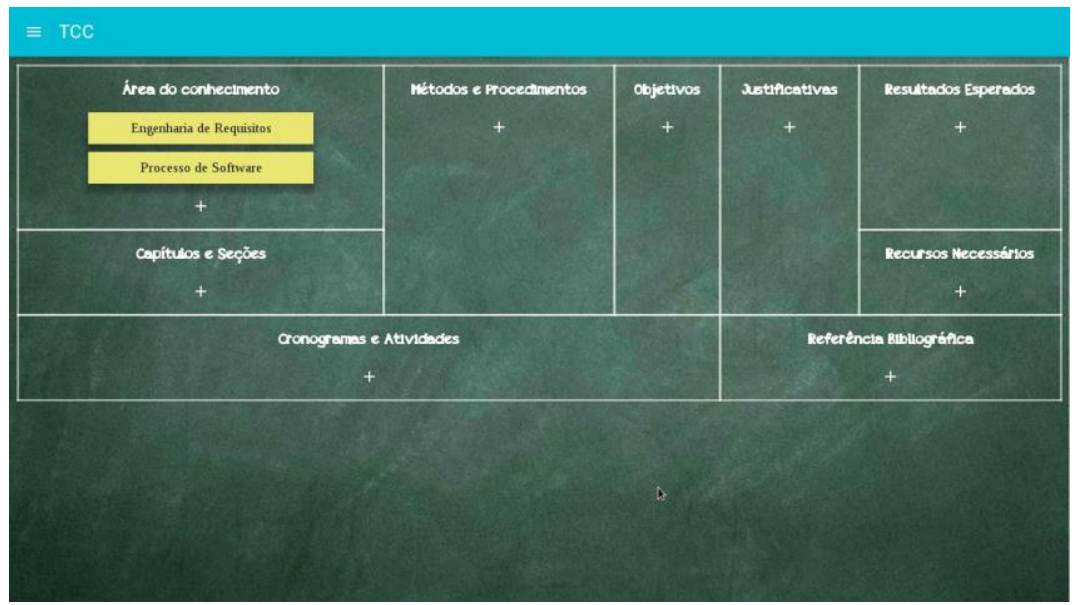

Figura 6: Ideias iniciais no Canvas Acadêmico

A cada usuário é atribuída uma cor de post-it virtual, de modo que em caso de compartilhamento do projeto com outros alunos e/ou professores se possa diferenciar as ideias de cada um pela cor. Uma ferramenta que auxilia comentários e correções do orientador para ajudar a fazer o trabalho acadêmico tomar forma. Pode-se observar a utilização desse recurso conforme a figura 7 abaixo:

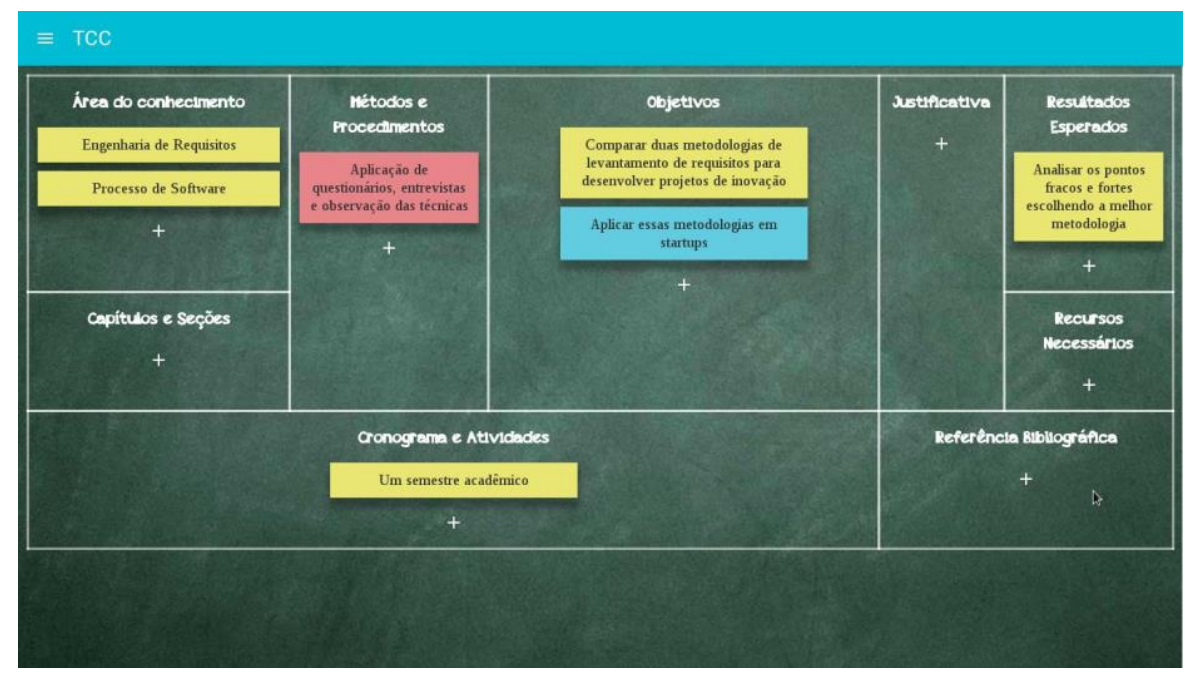

Figura 7: Canvas Acadêmico compartilhado com post-its coloridos para diferenciar usuários

Após a estruturação completa das ideias do projeto, alunos e professores poderão se dedicar a construção do trabalho acadêmico em si, conforme normas e formatos necessários. O objetivo do Canvas Acadêmico é possibilitar um ambiente colaborativo virtual para que se possam esboçar e estruturar as primeiras ideias referentes a pesquisas e trabalhos acadêmicos, para posterior construção de modo mais eficiente e simplificado. 
V Congresso Brasileiro de Informática na Educação (CBIE 2016)

Anais dos Workshops do V Congresso Brasileiro de Informática na Educação (CBIE 2016)

\section{Considerações finais}

A criação de objetos de apoio a aprendizagem é muito importante para o suporte à alunos e professores. Neste projeto propõe-se o uso de um Canvas composto de elementos acadêmicos, ao invés de elementos de modelagem de negócios, para auxiliar no entendimento dos itens que compõem projetos e trabalhos acadêmicos, como objetivo, justificativa e metodologia, os quais, muitas vezes, são mal compreendidos no modelo de ensino tradicional.

Através do uso destes recursos pedagógicos, onde o aluno poderá desenvolver os itens do Canvas Acadêmico de forma interativa, será possível promover a criatividade e o raciocínio lógico, ao preencher os itens que compreendem um trabalho acadêmico, de forma sistematizada, entendendo o conteúdo de cada um e a relação entre eles. Também poderá facilitar o trabalho dos professores que poderão utilizar essa ferramenta para discutir os trabalhos com os orientados e propor alterações e melhorias de forma simplificada.

Nesta fase inicial de validações percebeu-se, por parte dos usuários iniciais, o interesse e aprovação do modelo proposto, visto sua simplicidade de facilidades de uso e compartilhamento de recursos.

A partir do uso contínuo do Canvas Acadêmico através de suas versões, será possível realizar melhorias contínuas e até mesmo implementar novas funcionalidades e benefícios sugeridos pelos usuários, que são os grandes parceiros deste projeto.

Como trabalhos futuros, espera-se melhorar também os recursos de gestão de informações e arquivos relacionados ao projeto, dando possibilidade para que alunos e professores possam utilizar o ambiente Canvas Acadêmico também como um repositório de arquivos, visando facilitar a organização de sua rotina acadêmica.

Além disso, o uso frequente do Canvas deverá aproximar o acadêmico, durante sua fase de aprendizado profissional, da visão empresarial de forma sistematizada, utilizada no modelo Canvas de Modelo de Negócios, possibilitando seu interesse pelo mundo do empreendedorismo ainda em ambiente acadêmico e facilitando a transição da construção de seus projetos acadêmicos para futuros projetos empreendedores.

\section{References}

Clark, T. (2013) Business Model You: O Modelo de Negócios Pessoal, 1ª ed. Alta Books.

Junior, J. F. (2013) Project Model Canvas - Gerenciamento de Projetos Sem Burocracia, Elsevier - Campus, 229 p., $4^{\mathrm{a}} \mathrm{ed}$.

Osterwalder, A., (2004) The business model ontology: A proposition in a design science approach. Tese, Université de Lausanne, Suiça.

Osterwalder, A., Pigneur, Y., (2010) Business Model Generation: A handbook for visionaires, game changers and challengers, $1^{\text {a }}$. ed., Willey

Osterwalder, A., Bernarda, G., (2014) Value Proposition Design - Como Construir Propostas de Valor Inovadoras, HSM Editora 